\title{
Cross-Cultural/Linguistic Differences in the Prevalence of Developmental Dyslexia and the Hypothesis of Granularity and Transparency
}

\author{
Taeko N. Wydell \\ Centre for Cognition and NeuroImaging, Brunel University, Middlesex, \\ UK
}

\section{Introduction}

In this chapter, cross-cultural and cross-linguistic differences in the prevalence of developmental dyslexia will be discussed. In order to account for the differences, the Hypothesis of Granularity and Transparency postulated by Wydell and Butterworth (1999) will be revisited.

Developmental dyslexia is defined as a failure to acquire reading skills, despite adequate intelligence, education and sociocultural opportunity (Chrichey, 1975), and it is generally accepted that it is a neurobiological disorder with a genetic origin (e.g., Eden \& Moat, 2002; Fisher \& DeFries, 2002). It has been reported that up to $10-12 \%$ of children in the English speaking world suffer from developmental dyslexia (e.g., Shaywitz, Shaywitz, Fletcher, \& Escobar, 1990; Snowling, 2000). Extensive research has been conducted in order to ascertain the causes of dyslexia (and subsequently to develop intervention programmes), since dyslexia sufferers form a large minority group, and yet there seems to be no consensus amongst the researchers as to what causes developmental dyslexia.

Ramus (2003) reviewed recent empirical studies in relation to major theories accounting for the causes of developmental dyslexia, such as for example, the auditory processing (in particular, rapid or temporal processing) deficit hypothesis (e.g., Tallal, 1980; Share, Jorm, MacLean, \& Matthews, 2002); the visual processing deficit hypothesis including magnocellular dysfunction hypothesis (e.g., Hansen, Stein, Orde, Winter and Talcott, 2001; Stein, 2001; 2003); the motor control deficit hypothesis (e.g., Wolf, 2002) including the cerebellar dysfunction hypothesis (e.g., Nicholson, Fawcett, \& Dean, 2001); the general sensorimotor processing deficit hypothesis (e.g., Laasonen, Service, \& Virsu, 2001; 2002) and the phonological processing deficit hypothesis (e.g., Ramus, 2001; Snowling, 2000). In his succinctly written review, Ramus pointed out that behavioural genetic studies revealed that phonological deficits are highly heritable, whereas auditory and visual deficits are not (e.g., Davis, Gayan, Knopik, Smith, Cardon, Pennington, Olson, \& DeFries, 2001; Olson \& Datta, 2002), and concluded that "although the phonological deficit is still in need of a complete cognitive and neurological characterisation, the case for its causal role in the aetiology of the reading and writing disability of the great majority of dyslexic children is overwhelming" (p.216).

Indeed, many behavioural studies in English have found core phonological deficits in children with developmental dyslexia (e.g., Stanovich, 1988; Stanovich \& Siegel, 1994; 
Snowling 2000). The phonological deficits tend to interfere with the acquisition of appropriate grapheme-to-phoneme conversion skills. Moreover, adults with childhood diagnoses of dyslexia also revealed persistent phonological deficits (e.g., Bruck, 1992). For example, Felton, Naylor, and Wood (1990) found that adults with developmental dyslexia were impaired compared with normal controls using Rapid-Automatized-Naming (RAN), phonological awareness skills and non-word reading tests. Similarly, Paulesu, Frith, Snowling, Gallagher, Morton, Frackowiak and Frith (1996) found that even well-compensated dyslexic adults showed residual phonological deficits on phoneme deletions and Spoonerizing (exchange the initial phonemes of a pair of words, e.g., /car/ / park/ -> / par/ /cark/) tests.

\section{Dyslexia and poor phonological recoders}

More recently, Wydell in Shapiro, Hurry, Masterson, Wydell and Doctor (2009) tested 158 male and female students aged 14-15 in a state-funded selective and highly academic secondary school in the UK, and identified a subset students with phonological deficits.

The following five phonological tests (in written format) were administered to all the participating students: Rhyme-Judgements in words (e.g., YES to 'head-bed'), RhymeJudgement in nonwords (e.g., YES to 'kape-bap'), Homophone-Judgements in words (e.g., YES to 'their-there'), Homophone-Judgements in nonwords (e.g., YES to 'kane-kain'), Phonological-Lexical Decisions (e.g., YES to 'brane').

Wydell identified 16 students out of this cohort (approximately just over 10\%), whose scores on any of these tests fell more than 1.5 standard deviations (SD) below the mean of the group, as poor phonological recoder (PPR) readers (i.e., those with phonological deficits).

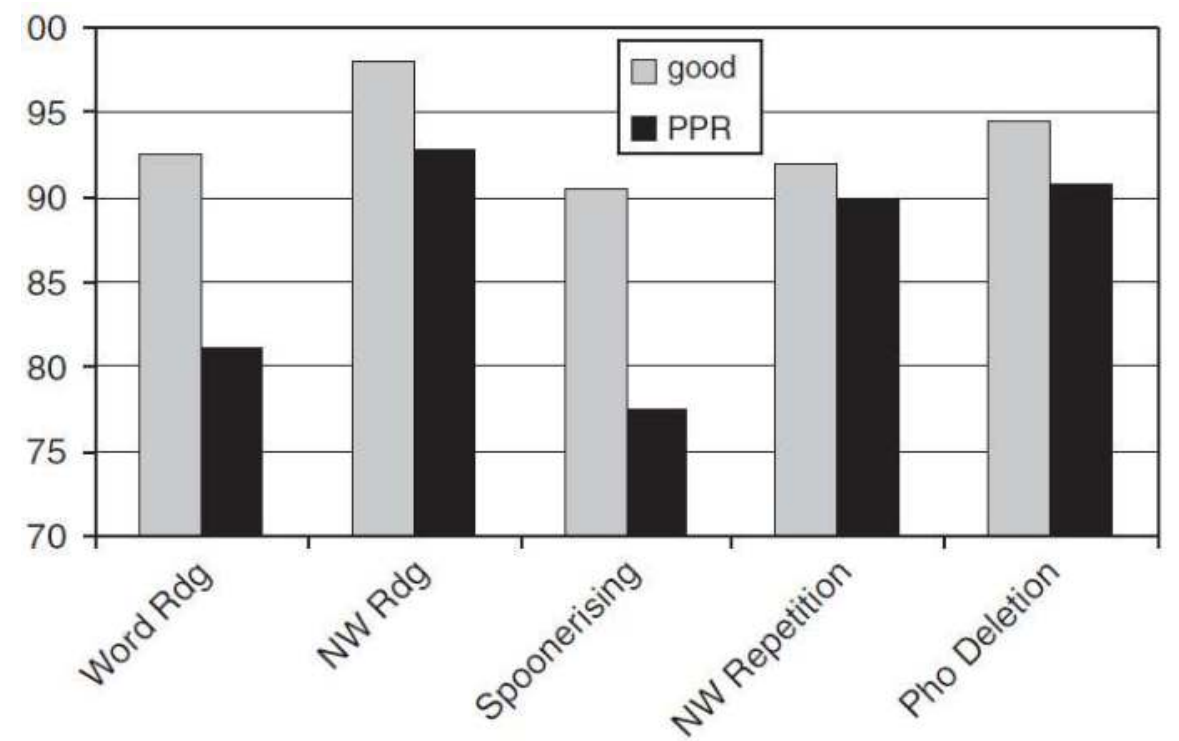

Note: The figure was extracted from Shapiro, Hurry, Masterson, Wydell and Doctor (2009).

Fig. 1. Proportion correct for reading and phonological tasks of PPR-Readers compared with that of the controls. 
Those PPR-readers and 16 randomly selected normal readers were further tested for their skills in Word Reading, Nonword Reading, Spoonerizing, Phoneme Deletions, and Nonword Repetition. As illustrated in Figure 1, the results revealed that PPR-readers were significantly worse than the controls on all the tests $(p>.01-p>.0001)$ except for Phoneme Deletions $(\mathrm{p}=.08)$ and Non-word repetition $(\mathrm{p}>1)$. Note that Gathercole and Baddeley's (1996) Non-word Repetition test is known to be one of the most effective diagnostic tools to identify developmental dyslexia in young children. Yet, this test did not show any difference between the PPR-readers and the normal controls. This might be because the test was developed primarily to assess young children's phonological skills, and that the test might not be sensitive enough for these adolescent individuals.

Furthermore, Wydell compared these PPR-readers' performance on SATs ${ }^{1}$ in English, Science and Mathematics individually, with that of the normal controls using z-scores 2 .

The results revealed that $60 \%$ of PPR-readers' SAT-English scores, and $70 \%$ of their SATScience scores were significantly lower than those of normal controls (both at $\mathrm{p}<.001$ ). In SAT-Maths scores, however, none of the PPR-readers were significantly worse than the controls, indicating that cognitive processes involved in reading may be different from those involved in mathematical operations (a similar pattern of data can be seen in the case study reported by Wydell \& Butterworth, 1999).

Wydell thus identified a subset of students aged 14-15 with phonological deficits even in a selective and competitive academic environment, where all students appeared to be performing well against the national average. Yet, these PPR-readers can still be considered as academic underachievers, as Hannell (2004) suggested.

\section{Dyslexia and the hypothesis of granularity and transparency}

Wydell and Butterworth (1999) reported the case of an adolescent English-Japanese bilingual male, AS, whose reading and writing difficulties are confined to English only. Extensive investigations into his reading/writing difficulties in English revealed that he has typical phonological processing deficits (Wydell \& Butterworth, 1999; Wydell \& Kondo, 2003). Figure 2 illustrates his performance in reading and phonological processing tests in English together with those of age-matched English and Japanese monolingual controls, which clearly indicate his phonological processing deficits.

However his ability to read Japanese was equivalent and often better than that of his Japanese peers, as illustrated in Table 1.

Note that the Japanese writing system consists of two qualitatively different scripts: logographic, morphographic Kanji, derived from Chinese characters, and two forms of syllabic Kana, Hiragana and Katakana which are derived from Kanji characters (see Wydell, Patterson, \& Humphreys, 1993 for more details). These three scripts are used to write different classes of words. Kanji characters are used for nouns and for the root morphemes

\footnotetext{
1 SATs - Standard Assessment Tests: national achievement tests given to all the children across the UK at the end of Year-2 (aged seven), Year-6 (aged 11) and Year-9 (aged 14).

2 This is because it has been reported that there are marked individual differences among children with developmental dyslexia both in terms of the extent of the severity and the nature of difficulties/impairments (e.g., Snowling \& Griffiths, 2005).
} 
of inflected verbs, adjectives and adverbs. Hiragana characters are used mainly for function words and the inflections of verbs, adjectives and adverbs, and for some nouns with uncommon Kanji representations. Katakana characters are used for the large number of foreign loan words (e.g. テレビ/terebi/TV) in contemporary Japanese.

Both forms of Kana have an almost perfect one-to-one relationship between character and pronunciation. That is, one character always represents one particular syllable or mora (syllable like unit) of the Japanese language and its sound value does not change whether the character appears in the first position, the middle position or at the end of a multisyllable word. This is different from English, where orthographic units not only map onto sub-syllabic phonological units, but the mapping will also depend on context, i.e. the location within the word.

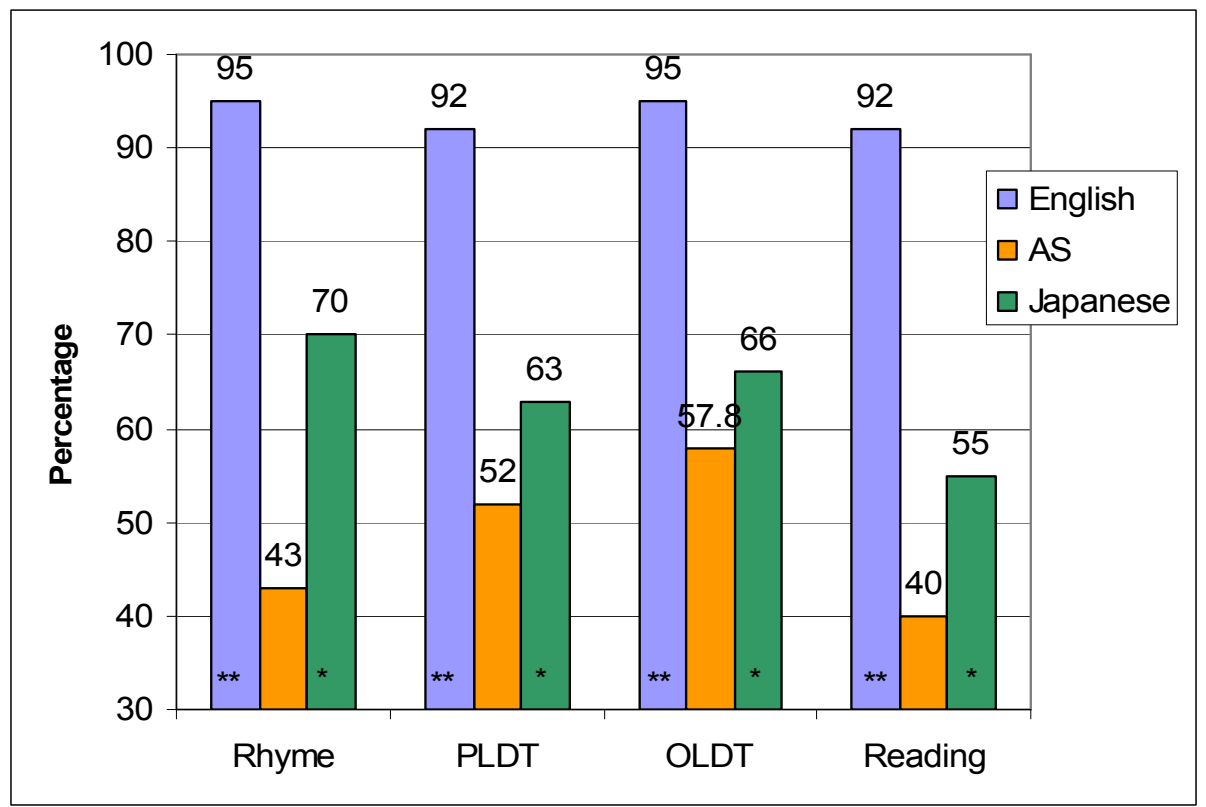

Note: These tests are in written format: Rhyme $=$ Rhyme judgements; PLDT $=$ Phonological lexical decision task (YES to psudohomophones, e.g., brane); PLDT = Orthographic lexical decision task (i.e., spell checking); Reading $=$ reading aloud. ${ }^{* *}=\mathrm{p}<.01 ;{ }^{*}=\mathrm{p}<.05$.

The data were extracted from Wydell and Kondo (2003).

Fig. 2. A comparison of AS's performance with that of Japanese and English monolingual controls for reading and phonological tests

Words in Kanji have 1-5 characters with two being the modal number, and 2.4 the mean.

The relationship between character and pronunciation in Kanji is very opaque. This is because each Kanji character is a morphographic element that cannot phonetically be decomposed in the way that an alphabetic word can be. There are no separate components of a character that correspond to the individual phonemes (see Wydell, Patterson \& Butterworth, 1995 for a further discussion). Also, most Kanji characters have one or more ON-readings, 
(pronunciations that were imported from spoken Chinese along with their corresponding characters) as well as a KUN-reading from the original Japanese spoken language. Some characters have no KUN-reading, but for those which have, the KUN-reading is almost always the correct reading when this character constitutes a word on its own (e.g., 花/hana/ in KUNreading, meaning 'flower' which represents a single-character word; 花束/hana-taba/ in KUN-reading, meaning 'bouquet' vs. 花瓶/ka-bin/ in ON-reading, meaning 'vase').

\begin{tabular}{|c|c|c|c|c|c|c|}
\hline \multirow[t]{3}{*}{ Word type } & AS & \multicolumn{2}{|c|}{ (Control) } & AS & \multicolumn{2}{|c|}{ (Control) } \\
\hline & \multicolumn{3}{|c|}{ High frequency $(n=40)$} & \multicolumn{3}{|c|}{ Low frequency $(n=40)$} \\
\hline & & S.7 & S.14 & & S.7 & S.14 \\
\hline Consistent & $95 \%$ & $(99.2 \%)$ & & $95 \%$ & $(97.9 \%)$ & \\
\hline RT (ms) & 880 & 814 & 924 & 800 & 786 & 776 \\
\hline Inc-ON & $100 \%$ & $(98.7 \%)$ & & $90 \%$ & $(89.2 \%)$ & \\
\hline $\mathrm{RT}(\mathrm{ms})$ & 883 & 813 & 812 & 802 & 760 & 810 \\
\hline Inc-KUN & $100 \%$ & $(97.9 \%)$ & & $80 \%$ & $(87.2 \%)$ & \\
\hline RT (ms) & 965 & 919 & 1377 & 838 & 791 & 916 \\
\hline Jukujikun & $85 \%$ & $(89.2 \%)$ & & $60 \% *$ & $(81.7 \%)$ & \\
\hline RT (ms) & 1070 & 1119 & 1215 & 843 & 960 & 1052 \\
\hline
\end{tabular}

*Outside of the range of normal adults (aged between 20 and 54 years, mean age 31 years). The control data are the adult data from Wydell et al. (1997).

Note: Consistent $=$ each character in a two-character Kanji word has one invariant ON (or occasionally KUN)-reading; Inc-ON (Inconsistent ON-reading) = each character takes ON-reading in a two-character word, but each character has a KUN-reading and/ or another ON-reading; Inc-KUN (Inconsistent KUN) $=$ each character takes KUN-reading in a two-character word, but each character has at least one ONreading; Jukujikun = truly exception words, neither character in a two-character Kanji word takes typical ON or KUN-reading, e.g., 雪崩/nadare/ meaning 'avalanche' however the first character means 'snow', and it is /yuki/ in KUN-reading, while it is / setsu/ in ON-reading; the second character means 'collapse', and it is / kuzu/ in KUN-reading, while it is /hou/ in ON-reading.

The table was extracted from Wydell \& Butterworth (1999).

Table 1. AS's Performance for two-character Kanji word naming

Table 1 shows that his accuracy in reading two-character Kanji words is equivalent to Japanese undergraduate level except for low familiar Jukujikun $(z=-3.63, P, 0.0009)$. Wydell and Butterworth stated that the latter may be due to the fact that he had not had enough exposure to low familiar Jukujikun. When AS was tested with these words, he was 16 years old, while the youngest participant who took part in the experiment of Wydell, Butterworth, Shibahara and Zorzi (1997) was 20 years old (mean age was 31 years old). Kanji learning is essentially a life-long continuous learning process. If he were continuously educated within the Japanese educational system, he would most probably be able to read these low familiar Jukujikun by the time he graduated from a Japanese university.

In order to account for the dissociation between his ability to read in English and Japanese, Wydell and Butterworth (1999) put forward the Hypothesis of Granularity ${ }^{3}$ and

${ }^{3}$ In their review paper, Ziegler and Goswami (2005) also pointed out the importance of 'granularity' in order to explain developmental dyslexia across different languages, and postulated the "Psycholinguistic grain size theory", which, however, "does not predict that orthographic consistency 
Transparency as illustrated in Figure 3. The hypothesis maintains that orthographies can be described in these two dimensions - (1) any orthography, where the print-to-sound translation is one-to-one or transparent would not produce a high incidence of phonological dyslexia (i.e., dyslexia due to phonological deficits) regardless of the level of translation, i.e. phoneme, syllable, character, etc. This is the 'transparency' dimension, and (2) even when this relationship is opaque and not one-to-one, any orthography whose smallest orthographic unit representing sound is coarse, i.e. a whole character or whole word, would not produce a high incidence of phonological dyslexia. This is the 'granularity' dimension. Any orthography used in any language can be placed in the transparency-granularity orthogonal dimension described by this hypothesis.

\section{Granular Size}

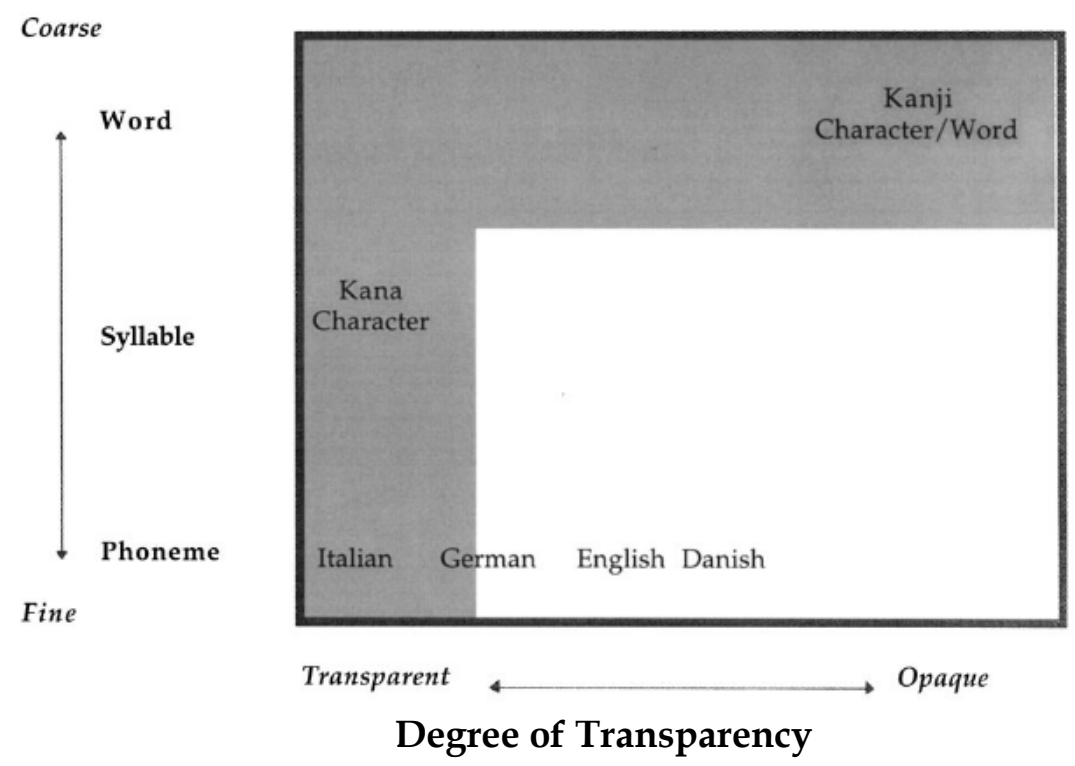

Fig. 3. Hypothesis of Granularity and Transparency and orthography-to-phonology correspondence.

For example, the granularity of the smallest orthographic unit representing phonology for Japanese Kana is finer than the whole word, but coarser than the grapheme, and its orthography-to-phonology mapping is at the level of syllables and one-to-one. In contrast, for Japanese Kanji, the unit of granularity is much coarser, i.e. a character or a whole word,

(i.e., transparency) reduced developmental dyslexia" (p.20). They further argued that had Wydell and Butterworth included nonword reading tasks in terms of "timed performance", he (AS) would have "displayed clear deficits in reading" in both languages (p.20). However, Zigler and Goswami did not include Wydell and Kondo (2003)'s follow-up study in their review paper. Wydell and Kondo stated that "AS's reading was never laborious and slow" (p.40). Although they did not measure RT for each stimulus word or nonword in milliseconds, they measured AS's reading latencies for stimulus lists (in minutes/seconds), which included nonwords in English and Japanese Kana. AS's reading latencies were comparable to those of the English controls, and were shorter than those of the Japanese controls. 
and the orthography -to-phonology mapping is very opaque, hence Kanji can be placed in the shaded area. By this hypothesis, therefore, either of the two scripts used in Japanese should not lead to a high incidence of phonological dyslexia.

Now with this categorisation, English can be placed outside of the shaded area, since the granularity for English is small/finer, however, the orthography-to-phonology mapping is not always one-to-one and not transparent. By this hypothesis, English orthography may lead to a high incidence of phonological dyslexia. Given the differences between the two orthographies used in Japanese and English, therefore, the hypothesis of granularity and transparency argues that it might be possible for an English-Japanese bilingual individual to be dyslexic in English but not in Japanese.

\section{Prevalence of dyslexia and the hypothesis of granularity and transparency}

Indeed, researchers have argued that the difference in the prevalence of developmental dyslexia in the different languages might be primarily due to the differences inherent in the characteristics of each orthography, in particular, the way in which phonology is computed from orthography (e.g., de Luca, Burani, Paizi, Spinelli, Zoccolotti, 2010; Landerl, Wimmer, Frith, 1997; Wydell \& Butterworth, 1999; Zoccolotti, de Luca, de Pace, Gasperini, Judica, Spinelli, 2005). Earlier it was mentioned that in English up to $10-12 \%$ of children are reported to suffer from developmental dyslexia (e.g., Shaywitz, et al., 1990; Snowling, 2000). In Danish, as many as $12 \%$ of adults in Denmark have difficulties in reading, which was revealed in the study conducted by Elbro, Moller, and Nielsen (1995). In these languages, orthography-to-phonology correspondence (which means grapheme-to-phoneme correspondence in alphabetic languages) is not consistent, i.e., not always one-to-one or transparent (e.g., hint, lint, tint vs. pint; bread, head vs. bead, mead; colonel; yacht; bough vs. dough vs. through vs. thorough). However, in alphabetical languages whereby the grapheme-to-phoneme correspondence is consistent or transparent, such as for example, Dutch, German, or Italian, the prevalence of developmental dyslexia is much lower (e.g., de Luca, et al., 2010; Zoccolotti et al., 2005 for Italian; Landerl, et al., 1997 for the comparison between German and English speakers; Paulesu, De'monet, Fazio, McCrory, Chanoine, Brunswick, Cappa, Cossu, Habib, Frith, C.D., \& Frith U., 2001 for the comparison between English, French and Italian speakers).

For example, Landerl et al. (1997) examined the reading and phonological processing skills of English and German dyslexic children against their normal chronological and reading age-matched controls, and found that although the same underlying phonological processing deficit might exist in both German and English dyslexic children, there were differences in the severity of the reading impairment. English dyslexic children showed a marked adverse effect in the acquisition of reading skills compared to German dyslexic children. These differences were also seen between the normal German and English control children in their reading performance. Landerl et al. suggested that these differences were due to differences in orthographic 'consistency'. That is, different orthographies have different mapping rules, and there is a wide range in the degree of consistency with which alphabets represent phonemes by graphemes. 'Consistency' here is interchangeable with 'transparency'. For orthographies such as German, Italian or Spanish, the grapheme-tophoneme mapping is, in general, one-to-one, and consistent/transparent. For other orthographies such as English or Danish, the grapheme-to-phoneme mapping is often one- 
to-many (e.g., food vs. hood vs. flood or blood), and less consistent/transparent (e.g. Seidenberg, Waters, Barnes, \& Tanenhaus, 1984). Thus it was assumed that orthographic consistency/transparency affects both the nature and degree of reading difficulties (de Luca, et al., 2010; Zoccolotti et al., 2005).

Landerl et al. further argued that phonological recoding itself may not necessarily be a demanding task. When grapheme-to-phoneme mapping is consistent/transparent, children can easily acquire the grapheme-phoneme correspondence rules, and use these to assemble pronunciations for novel letter strings (as seen with Italian or Spanish children for example). Therefore, the phonological recoding may become a demanding task, only when the grapheme-phoneme correspondence in an orthography is not consistent/transparent, such as for example, English (Snowling, 2000) or Danish (Elbo et al., 1995). Therefore, if the grapheme-phoneme correspondence is consistent, even children with phonological deficits may be able to learn to map print onto sound thus without showing a delay in reading acquisition. Similarly, the 'hypothesis of granularity and transparency' in particular, the transparency dimension predicts that developmental phonological dyslexia should not manifest itself in a writing system where the print-to-sound correspondence is transparent regardless of the size unit of granularity.

Moreover, the granularity dimension of the hypothesis predicts that developmental phonological dyslexia should not manifest itself in a writing system where the unit of granularity is coarse at a whole character or whole word level. It should therefore be possible to find a bilingual individual with monolingual dyslexia, especially between two orthographies such as English and Japanese.

Further evidence which lends support to the Hypothesis can be seen in a recent cross sectional study conducted in Japanese by Uno, Wydell, Haruhara, Kaneko and Shinya (2009). In their study, 495 Japanese primary school children (from $2^{\text {nd }}$ Grade aged eight to $6^{\text {th }}$ Grade aged 12) in Japan were tested for their reading, writing and other cognitive skills including phonological awareness (STRAW, 2006). The results showed that percentages of children who had reading difficulties (defined as those whose reading/writing/phonological tests' scores fell below -1.5SD) in syllabic Hiragana, syllabic Katakana, and logographic Kanji were $0.2 \%, 1.4 \%$, and $6.9 \%$ respectively - these figures were significantly lower than those reported in the studies in English (Shaywitz et al., 1997; Snowling, 2000) or Danish (Elbo et al., 1995). Yet there was no significant difference in the IQ scores between the normal group and reading/writing disabled (RWD) group (measured by Ravens Coloured Progressive Matrices, 1976).

The study also suggested that different reading strategies might be adopted when reading in Kana and Kanji. For Kana, where the character-to-sound-mapping is transparent, a simple on-line phonological processing (i.e., sublexical analytical reading) strategy might be used (Wydell \& Butterworth, 1999; Rastle, Havelka, Wydell, Coltheart, Besner 2009), just like other consistent orthographies such as Italian (de Luca, et al., 2010; Zoccolotti et al., 2005) or German (Landerl et al., 1997). In contrast, for Kanji, because the character-to-soundrelationship is opaque, and the correct pronunciation is determined at the whole-word level, a lexical whole-word reading strategy might be used (e.g., Morton, Sasanuma, Patterson \& Sakuma, 1992; Wydell, 1998; Wydell \& Butterworth, 1999; Wydell, et al., 1993; Wydell, Butterworth \& Patterson, 1995; however also see Fushimi, Ijuin, Patterson \& Tatsumi, 1999 for counter argument). 
Thus the results of Uno et al.'s (2009) study further lend support to the Hypothesis of Granularity and Transparency. Wydell and Butterworth (1999) argued that English orthography would require a fine tuning of the orthography-to-phonology mapping, because English orthography is not completely transparent at the subsyllabic level (i.e. smaller grain-unit than syllables). In contrast, the grain size for Kana is at the whole character level (i.e., greater grain-unit than graphemes), and its orthography-to-phonology mapping is transparent (one-to-one). Hence Japanese children in general find it easier to master reading in Kana. This is because, as Landerl et al. (1997) argued for German, the phonological recoding of Kana is not a demanding task. Moreover, although the grain size for Kanji is either at whole character or whole word level, its orthography-to-phonology mapping is opaque (one-to-many). Consequently learning to read in Kanji for Japanese children is harder than that in Kana. The results thus indicate that reading Kanji may require different reading strategies or different cognitive skills to those required for reading Kana. If so, reading English may yet require different reading strategies to those required for Kanji or Kana.

Wydell and Butterworth (1999) thus speculated that it is therefore possible to be a Danish or English-Japanese bilingual with monolingual dyslexia in Danish or English.

\section{Dyslexia and cross-cultural and cross-linguistic differences}

Interestingly, in Japan rather than group studies, single case studies of children with reading disorders have started to emerge (e.g., Kaneko, Uno, Kaga, Matsuda, Inagaki, \& Haruhara, 1997; 1998; Uno, Kaneko, Haruhara, Matsuda, Kato, \& Kasahara, 2002). The majority of these children in Japan tend to have both reading and writing difficulties, and often the writing impairment is more severe than the reading impairment ${ }^{4}$. Significantly, in Japan there are very few reported cases of children with reading impairments only. The Japanese researchers usually attribute these reading and writing impairments among children to 'visual' or 'visuospatial' processing problems (e.g., Kaneko et al., 1998) rather than phonological processing problems.

Unlike alphabetic orthographies but similar to Japanese KANJI, the Chinese language uses a logographic writing system whereby the basic orthographic units, the Chinese characters, correspond directly to morphemic meanings and to syllables in the spoken language. The pronunciations of Chinese characters are represented at the monosyllabic level, and no phonemes are represented in a character. That is, reading a Chinese character does not allow the segmental analysis (i.e., grapheme-to-phoneme conversion), which is fundamental in alphabetic orthographies (Wanga, Bi, Gao, \&Wydell, 2010). Therefore Chinese is often referred as a morphosyllabic writing system (Shu \& Anderson, 1997). Further, Meng, Sai, Wang X., Wang, J., Sha, and Zhou (2005) pointed out that there is only limited systematic correspondence between orthography and phonology. Moreover, Mandarin Chinese has a large number of homophonic morphemes and homophonic characters. Therefore it is often stated that the use of phonological information may not be as critical in reading Chinese as it is in reading alphabetic languages (Ho, Chan, Lee, Tsang, \& Luan, 2004; Ho, Chan, Tsang, \& Lee, 2002; Shu, McBride-Chang, $\mathrm{Wu}, \& \mathrm{Liu}, 2006)$. If this were the case, then a high incidence

${ }^{4}$ In English, it is often the case that when reading is impaired, writing is also impaired, and therefore dyslexia is assumed to mean both reading and writing impairments. 
of phonological dyslexia in Chinese should not be seen ( $c f$ the Hypothesis of Granularity and Transparency (Wydell \& Butterworth, 1999)).

Similar to Uno et al.'s (2009) study in Japanese, Li, Shu, McBride-Chang, Liu and Peng (in press) investigated the acquisition of reading in Chinese, and tested 184 kindergarten children and 273 primary school children from Beijing, Mainland China for their skills in (a) Chinese character recognition, (b) visual-spatial relationships and visual memory, (c) orthographic judgement, (d) phonological awareness including (d1) Rime deletion, (d2) Syllable deletion, (d3) Phoneme deletion and (d4) Rapid number naming, (e) Morphological awareness including (e1) Homophone judgements, (e2) Morphological construction, and (e3) Morpheme production.

The results showed that especially for the primary school children, a unique and relatively strong relationship between (c) orthographic knowledge (and not (b) visual skills) and reading was found. In addition, (d) phonological and (e) morphological awareness "appear to be somewhat important for reading throughout the very beginning and intermediate periods of character acquisition" (p.15). However, (d3) phoneme deletion was not uniquely associated with reading particularly for the primary school children. Li et al. thus argued that "phoneme awareness by itself is relatively unimportant for reading Chinese because the phoneme is not explicitly represented in the Chinese orthography" (p.16). Li et al. further argued that unlike most alphabetic writing systems where there is a strong relationship between phoneme awareness and reading skills, in Chinese larger unit size such as syllable or rime may be a better predictor variable for reading Chinese characters.

Indeed, recent research has revealed that the major cause of developmental dyslexia in Chinese is a deficit in orthographic processing skills, rather than in phonological processing skills (e.g., Chan, Ho, Tsang, Lee, \& Chung, 2006; Ho et al., 2004; Shu et al., 2006), though some studies did show that Chinese dyslexic children had phonological deficits (e.g., deficits in rapid naming (e.g., Ho, Law, \& Ng, 2000) and auditory processing (e.g., Meng et al., 2005).

In order to ascertain neurophysiologically a cause of developmental dyslexia in Chinese, Wang, Bi, Gao, and Wydell (2010) conducted an ERP (Event Related Potential) study with Chinese dyslexic and chronological-age-matched, and reading-level-matched non-dyslexic children from Beijing, Mainland China, employing a psychophysical experiment, i.e., the motion-onset paradigm. A similar psychophysical paradigm was first employed by RogersRamachandran and Ramachandran (1998) with English-speakers as their participants, whereby two distinct visual systems/pathways in human vision were identified, namely, "a fast, sign-invariant system concerned with extracting controls" (p.71) which is the magnocellular visual system, and "a shallower, sign-sensitive system concerned with assigning surface colour" (p.71), which is the parvocellular visual system. Subsequent similar psychophysics studies with English-speaking children as participants showed that the performance of the participating children significantly correlated with the measures of orthographic skills in the Magnocellular Condition (e.g., Sperling, Lu, Manis, and Seidenberg, 2003; Talcott, Witton, McLean, Hansen, Rees, \& Green, 2000).

Wang et al.'s ERP study revealed that the Chinese dyslexic children's orthographic processing skills were significantly compromised, when compared to their Chinese chronological and reading age-matched control children, which in turn, Wang et al. argued, is linked to a deficit in the visual magnocelluar system. 
Other brain imaging studies using fMRI (functional Magnetic Resonance Imaging) in Chinese such as Siok, Niu, Jin, Perfetti, and Tan (2008) or Siok, Perfetti, Jin, \& Tan (2004) revealed functional and structural abnormalities in the left middle frontal gyrus of Chinese dyslexic children, but not in the left temporoparietal and occipitotemporal regions that are important for reading in alphabetic languages (e.g., Paulesu, McCrory, et al., 2000; Wydell, Vuorinen, Helenius \& Salmelin, 2003), and are typically compromised in dyslexic children in alphabetic languages (e.g., Horwitz, Rumsey, \& Donohue, 1998; Temple, Poldrack, Salidis, Deutsch, Tallall, Merzenich, \& Gabriel, 2001). These researchers therefore argued that reading Chinese characters might require firstly greater cognitive demand for visual processing than reading in alphabetic languages such as English, and secondly a greater inter-activity between orthography and phonology. This is because, like Japanese Kanji, reading Chinese characters requires retrieving phonology as a whole rather than addressing phonology in piece-meal fashion (see Wang et al., 2010 for more details). Therefore Siok and his colleagues also suggested that the neural abnormality found in impaired readers is dependent on culture (see also Paulesu, Frith, et al., 2001 for a similar argument).

Thus in this Chapter, having reviewed recent empirical studies in alphabetical as well as non-alphabetic languages such as Chinese and Japanese, the chapter has shown significant cross-cultural/linguistic differences in the prevalence of developmental dyslexia in different languages.

\section{References}

Bruck, M. (1992). Persistence of dyslexics' phonological awareness deficits. Developmental Psychology, 28, 874-886.

Chan, D.W., Ho, C.S.H., Tsang, S.M., Lee, S.H., \& Chung, K.K.H. (2006). Exploring the reading-writing connection in Chinese children with dyslexia in Hong Kong. Reading and Writing, 19(6), 543-561.

Chrichey, M. (1975). Specific developmental dyslexia. In: Lenneberg, E.H., Lenneberg, E. (Eds.), Foundations of Language Development, Vol. 2. Academic Press, New York.

Davis, C.J., Gayan, J., Knopik, V.S., Smith, S.D., Cardon, L.R., Pennington, B.F., Olson, R.K., \& DeFries, J.C. (2001). Etiology of reading difficulties and rapid naming: the Coloradotwin study of reading disability. Behavioral Genetics, 31:625-635.

de Luca M, Burani C, Paizi D, Spinelli D, Zoccolotti P. (2010). Letter and letter-string processing in developmental dyslexia. Cortex 46, 1272-83.

Eden, G., \& Moats, L. (2002). The role of neuroscience in the remediation of students with dyslexia. Nature Neuroscience, 5, 1080-1084.

Elbo, C., Moller, S., \& Nielsen, E.M., (1995). Functional reading difficulties in Denmark: a study of adult reading of common text. Reading and Writing 7, 257-276.

Felton, R. H., Naylor, C. E., \& Wood, F. B. (1990). Neuropsychological profile of adult dyslexia. Brain and Language, 39, 485-497.

Fisher, S. E., \& DeFries, J. (2002). Developmental dyslexia: genetic dissection of a complex cognitive trait. Nature Reviews Neuroscience, 3, 767-780.

Fushimi, T., Ijuin, M., Patterson, K., \& Tatsumi, I. (1999). Consistency, frequency, and lexicality effects in naming Japanese Kanji. Journal of Experimental Psychology: Human Perception and Performance, 25, 382-407.

Gathercole, S.E., \& Baddeley, A.D. (1996). The Children's Test of Nonword Repetition. London: The Psychological Corporation. 
Hannell, G. (2004). Dyslexia: Action plans for successful learning. Great Britain: David Fulton Publishers.

Hansen, P.C., Stein, J.F., Orde, S.R., Winter, J.L., \& Talcott, J.B. (2001). Are dyslexics' visual deficits limited to measures of dorsal stream function? NeuroReport, 12:1527-1530.

Ho, C. S. H., Chan, D. W. O., Lee, S. H., Tsang, S. M., \& Luan, V. V. H. (2004). Cognitive profiling and preliminary subtyping in Chinese developmental dyslexia. Cognition, 91(1), 43-75.

Ho, C. S. H., Chan, D. W. O., Tsang, S. M., \& Lee, S. H. (2002). The cognitive profile and multiple-deficit hypothesis in Chinese developmental dyslexia. Developmental Psychology, 38(4), 543-553.

Ho, C. S. H., Law, T. P. S., \& Ng, P. M. (2000). The phonological deficit hypothesis in Chinese developmental dyslexia. Reading and Writing, 13(1-2), 57-79.

Horwitz, B., Rumsey, J. M. \& Donohue, B. C. (1998). Functional connectivity of the angular gyrus in normal reading and dyslexia. Proceeding of the National Academy of Sciences, USA, 95, 8939-8944 (1998).

Kaneko, M., Uno, A., Kaga, M., Matsuda, H., Inagaki, M., Haruhara, N. (1997). Developmental dyslexia and dysgraphia: a case report (in Japanese). NO TO HATTATSU (Brain and Child Development) 29, 249-253.

Kaneko, M., Uno, A., Kaga, M., Matsuda, H., Inagaki, M., Haruhara, N. (1998). Cognitive Neuropsycho-logical and Regional Cerebral Blood Flow Study of a Developmentally Dyslexic Japanese Child. Journal of Child Neurology Brief Communications 13, 9.

Laasonen, M., Service, E., \& Virsu, V. (2001). Temporal order and processing acuity of visual, auditory, and tactile perception in developmental dyslexic young adults. Cogn Affect Behav Neurosi, 1; 394-410.

Laasonen, M., Service, E., \& Virsu, V. (2002). Crossmodal temporal order and processing acuity in developmental dyslexic young adults. Brain \& Language, 80, 340-354.

Landerl, K., Wimmer, H., \& Frith, U. (1997). The impact of orthographic consistency on dyslexia: a German-English comparison. Cognition 63, 315-334.

Li, H., Shu, H., McBride-Chang, C., Liu, H., \& Peng, H. (in press). Chinese children's character recognition: Visuo-orthographic, phonological processing and morphological skills. Journal of Research in Reading. DOI: 10.1111/j.14679817.2010.01460.x

Meng, X. Z., Sai, X. G., Wang, C. X., Wang, J., Sha, S. Y., \& Zhou, X. L. (2005). Auditory and speech processing and reading development in Chinese school children: Behavioural and ERP evidence. Dyslexia, 11(4), 292-310.

Morton, J., Sasanuma, S., Patterson, K., \& Sakuma, N. (1992). The organisation of lexicon in Japanese: Single and compound Kanji. British Journal of Psychology 83, 517-531.

Nicolson, R.I., Fawcett, A.J., \& Dean, P. (2001). Dyslexia, development and the cerebellum. Trends in Neuroscience, 24:515-516.

Olson. R., \& Datta, H. (2002). Visual-temporal processing in readingdisabled and normal twins. Reading and Writing15:127-149.

Paulesu, E., Frith, U., Snowling, M., Gallagher, A., Morton, R.S.J., Frackowiak, R., \& Frith, C.D. (1996). Is developmental dyslexia a disconnection syndrome? Evidence from PET scanning. Brain 119, 143-157.

Paulesu, E., De'monet, J-F., Fazio, F., McCrory, E., Chanoine, V., Brunswick, N., Cappa, S.F., Cossu, G., Habib, M., Frith, C.D., \& Frith U. (2001). Dyslexia: cultural diversity and biological unity. Science, 291:2165-2167. 
Paulesu, E., Frith, U., Snowling, M., Gallagher, A., Morton, R.S.J., Frackowiak, R., \& Frith, C.D. (1996). Is developmental dyslexia a disconnection syndrome? Evidence from PET scanning. Brain 119, 143-157.

Paulesu, E., McCrory, E., Fazio, F., Menoncello, L., Brunswick, N., Cappa, S., Cotelli, M., Cossu, G., Corte, F., Lorusso, M., Pesenti, S., Gallagher, A., Perani, D., Price, C., Frith, C., \&Frith, U. (2000). A cultural effect on brain function. Nature Neuroscience, 3, 91-96.

Ramus, F. (2001). Outstanding questions about phonological processing in dyslexia. Dyslexia, 7; 125-149.

Ramus, F. (2003). Developmental dyslexia: specific phonological deficit or general sensorimotor dysfunction? Current Opinion in Neurobiology, 13, 212-218.

Rastle K, Havelka J, Wydell T, Coltheart M, \& Besner D. (2009). The cross-script length effect: Further evidence challenging PDP models of reading aloud. Journal of Experimental Psychology: Learning, Memory and Cognition 35, 238-46.

RCPM (Ravens Coloured Progressive Matrices) by Ravens (1976).

Rogers-Ramachandran, D. C., \& Ramachandran, V. S. (1998). Psychophysical evidence for boundary and surface systems in human vision. Vision Research, 38(1), 71-77.

Seidenberg, M.S., Waters, G.S., Barnes, M.A., \& Tanenhaus, M.K. (1984). When does irregular spelling or pronunciation incluence word recognition? Journal of Verbal Learning and Verbal Behavior, 23, 383-404.

Shapiro, L.R., Hurry, J., Masterson, J., Wydell, T.N., \& Doctor, E. (2009). Classroom implications of recent research into literacy development: from predictors to assessment. Dyslexia, 15 (1), 1-22.

Share, D.L., Jorm, A.F., MacLean, R., \& Matthews, R. (2002). Temporal processing and reading disability. Reading and Writing, 15:151-178.

Shaywitz, S. E., Shaywitz, B. A., Fletcher, J. M., \& Escobar, M. D. (1990). Reading disability in boys and girls. Journal of the American Medical Association, 264, 998-1002.

Shu, H. \& Anderson, R.C. (1997). Role of radical awareness in the characters and word acquisition of Chinese children. Reading Research Quarterly, 32(1), 78-89.

Shu, H., McBride-Chang, C., Wu, S., \& Liu, H. Y. (2006). Understanding Chinese developmental dyslexia: Morphological awareness as a core cognitive construct. Journal of Educational Psychology, 98(1), 122-133.

Snowling, M.J. (2000). Dyslexia. 2nd Edn. Oxford: Blackwell.

Siok, W. T., Niu, Z. D., Jin, Z., Perfetti, C. A., \& Tan, L. H. (2008). A structural-functional basis for dyslexia in the cortex of Chinese readers. Proceedings of the National Academy of Sciences of the USA, 105(14), 5561-5566.

Siok, W. T., Perfetti, C. A., Jin, Z., \&Tan, L. H. (2004). Biological abnormality of impaired reading is constrained by culture. Nature, 431(7004), 71-76.

Snowling, M. J., \& Griffiths, Y. M. (2005). Individual differences in dyslexia. In T. Nune \& P. E. Bryant (Eds.). Handbook of Literacy. Dordrecht: Kluwer Press.

Stanovich, K.E. (1988). Explaining the differences between the dyslexic and the gardenvariety poor reader: the phonological-core variable-difference model. Journal of Learning Disability, 21, 590-604.

Stanovich, K. E., \& Siegel, L. S. (1994). Phenotypic performance profile of children with reading disabilities: A regression-based test of the phonological-core variabledifference model. Journal of Educational Psychology, 86, 24-53.

Stein, J. (2001). The magnocellular theory of developmental dyslexia. Dyslexia, 7(1), 12-36.

Stein, J. (2003). Visual motion sensitivity and reading. Neuropsychologia, 41(13), 1785-1793.

STRAW (The Screening Test for Reading and Writing for Japanese Primary School Children) by Uno, Haruhara, Kaneko, \& Wydell (2006) 
Tallal, P. (1980). Auditory temporal perception, phonics, and reading disabilities in children. Brain and Language, 9(2), 182-198.

Talcott, J. B., Witton, C., McLean, M. F., Hansen, P. C., Rees, A., \& Green, G. G. R. (2000). Dynamic sensory sensitivity and children's word decoding skills. Proceedings of the National Academy of Sciences of the USA, 97(6), 2952-2957.

Temple, E., Poldrack, R.A., Salidis, J., Deutsch, G.K., Tallal, P., Merzenich, M.M., Gabriel, J.D.(2001). Disrupted neural responses to phonological and orthographic processing in dyslexic children: an fMRI study. Neuroreport, 12, 299-307.

Uno A, Kaneko M, Haruhara N, Matsuda H, Kato M, Kasahara, M. (2002) Developmental dyslexia: neuropsychological and cognitive- neuropsychological analysis (in Japanese). Shitsugoshoukenkyu 22, 130-6.

Uno, A., Wydell, T.N., Haruhara, N., Kaneko, M., \& Shinya, N. (2009). Relationship between reading/writing skills and cognitive abilities among Japanese primary-school children: normal readers versus poor readers (dyslexics). Reading $\mathcal{E}$ Writing 22, 755789. DOI 10.1007/s 11145-008-9128-8

Uno, A., Wydell, T.N., Kato, M., Itoh, K., \& Yoshino, F. (2009) Cognitive neuropsychological and regional cerebral blood flow study of a Japanese-English bilingual girl with specific language impairment (SLI). Cortex, 45:2, 154-163.

Wang, J-J., Bi, H-Y., Gao, L-Q., \& Wydell, T.N. (2010). The visual magnocellular pathway in Chinese-speaking children with developmental dyslexia. Neuropsychologia, 48; 36273633

Wolf, P.H. (2002). Timing precision and rhythm in developmental dyslexia. Reading and Writing, 15:179-206.

Wydell, T.N., \& Butterworth, B. (1999). An English-Japanese bilingual with monolingual dyslexia. Cognition, 70, 273-305

Wydell, T.N., Butterworth, B., Shibahara, N., Zorzi, M. (1997). The irregularity of regularity effects in reading: the case of Japanese Kanji. Paper presented at the meeting of the Experimental Psychology Society, Cardiff, UK.

Wydell, T. N., \& Kondo, T. (2003). Phonological deficit and the reliance on orthographic approximation for reading: A follow up study on an English-Japanese bilingual with monolingual dyslexia. Journal of Research in Reading, 26, 33-48.

Wydell, T.N., Butterworth, B.L., \& Patterson, K.E. (1995). The inconsistency of consistency effects in reading: Are there consistency effects in Kanji? Journal of Experimental Psychology: Language. Memory and Cognition, 21: 1156-1168.

Wydell, T.N., Patterson, K., \& Humphreys, G.W. (1993). Phonologically mediated access to meaning for KANJI: Is a ROWS still a ROSE in Japanese KANJI? Journal of Experimental Psychology: Learning, Memory and Cognition 19, 491-514.

Wydell, T.N., Vuorinen, T., Helenius, P., \& Salmeline, R. (2003). Neural Correlates of LetterString Length and Lexicality during reading in a regular orthography. Journal of Cognitive Neuroscience, 15:7, 1052-1062.

Ziegler, J.C. \& Goswami, U. (2005). Reading acquisition, developmental dyslexia, and skilled reading across languages: A psycholinguistic grain size theory. Psychological Bulletin, 131(1), 3-29

Zoccolotti, P., de Luca, M., de Pace, E., Gasperini, F., Judica, A., \& Spinelli, D. (2005). Word length effect in early reading and in develop-mental dyslexia. Brain $\mathcal{E}$ Language 93, 369-73. 


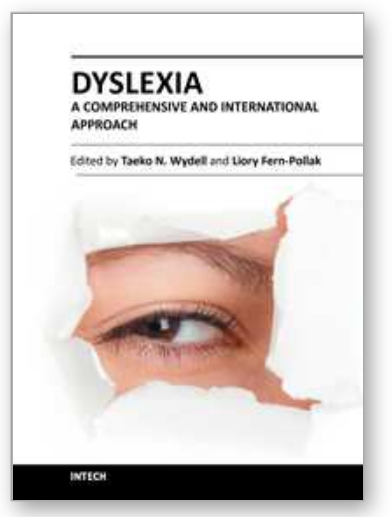

\author{
Dyslexia - A Comprehensive and International Approach \\ Edited by Prof. Taeko Wydell
}

ISBN 978-953-51-0517-6

Hard cover, 186 pages

Publisher InTech

Published online 18, April, 2012

Published in print edition April, 2012

This book brings together dyslexia research from different perspectives and from different parts of the world, with the aim of providing a valuable source of information to medical professionals specializing in paediatrics, audiology, psychiatry and neurology as well as general practitioners, to psychologists who specialise in developmental psychology, clinical psychology or educational psychology, to other professions such as school health professionals and educators, and to those who may be interested in research into developmental dyslexia. It provides a comprehensive overview of Developmental Dyslexia, its clinical presentation, pathophysiology and epidemiology, as well as detailed descriptions of particular aspects of the condition. It covers all aspects of the field from underlying aetiology to currently available, routinely used diagnostic tests and intervention strategies, and addresses important social, cultural and quality of life issues.

\title{
How to reference
}

In order to correctly reference this scholarly work, feel free to copy and paste the following:

Taeko N. Wydell (2012). Cross-Cultural/Linguistic Differences in the Prevalence of Developmental Dyslexia and the Hypothesis of Granularity and Transparency, Dyslexia - A Comprehensive and International Approach, Prof. Taeko Wydell (Ed.), ISBN: 978-953-51-0517-6, InTech, Available from:

http://www.intechopen.com/books/dyslexia-a-comprehensive-and-international-approach/cross-culturallinguistic-differences-in-the-prevalence-of-developmental-dyslexia-and-the-hypothesis

\section{INTECH}

open science | open minds

\section{InTech Europe}

University Campus STeP Ri

Slavka Krautzeka 83/A

51000 Rijeka, Croatia

Phone: +385 (51) 770447

Fax: +385 (51) 686166

www.intechopen.com

\section{InTech China}

Unit 405, Office Block, Hotel Equatorial Shanghai

No.65, Yan An Road (West), Shanghai, 200040, China 中国上海市延安西路65号上海国际贵都大饭店办公楼 405 单元

Phone: +86-21-62489820

Fax: +86-21-62489821 
(C) 2012 The Author(s). Licensee IntechOpen. This is an open access article distributed under the terms of the Creative Commons Attribution 3.0 License, which permits unrestricted use, distribution, and reproduction in any medium, provided the original work is properly cited. 